Old Dominion University

ODU Digital Commons

\title{
Videoconference Fatigue Exploring Changes in Fatigue after Videoconference Meetings during COVID-19
}

\author{
Andrew A. Bennett \\ Old Dominion University, aabennet@odu.edu \\ Emily D. Campion \\ Old Dominion University, ecampion@odu.edu \\ Kathleen R. Keeler \\ The Ohio State University, keeler.79@osu.edu \\ Sheila K. Keener \\ Old Dominion University, skeener@odu.edu
}

Follow this and additional works at: https://digitalcommons.odu.edu/management_fac_pubs

\section{Original Publication Citation}

Bennett, A. A., Campion, E. D., Keeler, K. R., \& Keener, S. K. (2021). Videoconference fatigue? Exploring changes in fatigue after videoconference meetings during COVID-19. Journal of Applied Psychology, 106(3), 330-344. https://doi.org/10.1037/apl0000906

This Article is brought to you for free and open access by the Department of Management at ODU Digital Commons. It has been accepted for inclusion in Management Faculty Publications by an authorized administrator of ODU Digital Commons. For more information, please contact digitalcommons@odu.edu. 
(C) 2021, American Psychological Association. This paper is not the copy of record and may not exactly replicate the final, authoritative version of the article. Please do not copy or cite without authors' permission. The final article will be available, upon publication, via its

DOI: $10.1037 /$ apl0000906

\section{Videoconference fatigue? Exploring changes in fatigue after videoconference meetings during COVID-19}

Andrew A. Bennett

Strome College of Business

Old Dominion University

2062 Constant Hall

Norfolk, VA 23529

Email: aabennet@odu.edu

Emily D. Campion

Strome College of Business

Old Dominion University

2030 Constant Hall

Norfolk, VA 23529

Email: ecampion@odu.edu

Kathleen R. Keeler

Fisher College of Business

The Ohio State University

754 Fisher Hall

2100 Neil Avenue

Columbus, OH 43210

Email: keeler.79@osu.edu

Sheila K. Keener

Strome College of Business

Old Dominion University

2037 Constant Hall

Norfolk, VA 23529

Email: skeener@odu.edu

Author Note: We thank Jaye Hughes, Sakshi Kale, Setareh Mohammadidehaghi, and Marijana Novakovic for their fantastic work as research assistants. We also greatly appreciate the tremendous time provided by our study participants. 


\title{
Videoconference fatigue? Exploring changes in fatigue after videoconference meetings during COVID-19
}

\begin{abstract}
In response to the COVID-19 global health pandemic, many employees transitioned to remote work, which included remote meetings. With this sudden shift, workers and the media began discussing videoconference fatigue, a potentially new phenomenon of feeling tired and exhausted attributed to a videoconference. In the present study, we examine the nature of videoconference fatigue, when this phenomenon occurs, and what videoconference characteristics are associated with fatigue using a mixed methods approach. Thematic analysis of qualitative responses indicates that videoconference fatigue exists, often in near temporal proximity to the videoconference, and is affected by various videoconference characteristics. Quantitative data was collected each hour during five workdays from 55 employees who were working remotely because of the COVID-19 pandemic. Latent growth modeling results suggest that videoconferences at different times of the day are related to deviations in employee fatigue beyond what is expected based on typical fatigue trajectories. Results from multilevel modeling of 279 videoconference meetings indicate that turning off the microphone and having higher feelings of group belongingness are related to lower post-videoconference fatigue. Additional analyses suggest that higher levels of group belongingness are the most consistent protective factor against videoconference fatigue. Such findings have immediate practical implications for workers and organizations as they continue to navigate the still relatively new terrain of remote work.
\end{abstract}

Keywords: Fatigue; Work meeting; Videoconference; COVID-19; Remote Work 


\section{Videoconference fatigue? Exploring changes in fatigue after videoconference meetings during COVID-19}

The onset of COVID-19 and the months-long shutdown accelerated the long-predicted trend of remote work (Niles, 1975; Raghuram et al., 2019). At its peak, one estimate reported that $70 \%$ of American workers operated remotely at least some of the time in April 2020 (World at Work, 2020), requiring workers to engage in remote meetings. While many workers have returned to their brick-and-mortar locations, others have not and continue to rely on remote meetings to complete their tasks, creating an urgency for scholars to research the implications of this context. One specific phenomenon in this context that emerged is videoconference fatigue ${ }^{l}$, which is the degree to which people feel exhausted or tired attributed to engaging in a videoconference. Recent evidence suggests that videoconferences are more fatiguing than inperson meetings because of increased sustained attention (Spataro, 2020). Reports of the videoconference fatigue phenomenon contrast with research that suggests people prefer remote meetings. For example, individuals believe in-person work meetings are an ineffective use of time (Geimer et al., 2015) and cause end-of-day fatigue (Luong \& Rogelberg, 2005), whereas videoconferences are viewed as more efficient (Lantz, 2001), shorter in duration (Denstadli et al., 2012), and are associated with higher performance on complex group tasks than in-person meetings (Rosetti \& Surynt, 1985). Videoconference fatigue could reduce these and other benefits, especially since lower employee energy is related to lower job performance and higher voluntary turnover (Wright \& Cropanzano, 1998) and is an indicator of reduced employee wellbeing (Bliese et al., 2017). Thus, to examine how to minimize this potentially negative outcome, we employ a mixed methods research design to explore the nature of videoconference fatigue,

\footnotetext{
${ }^{1}$ This has also been referred to as "Zoom fatigue" in reference to the virtual meeting interface Zoom (e.g., Fosslien \& Duffy, 2020; Jiang, 2020), but for future generalizability, we do not refer to it by its colloquial name.
} 
investigate temporal aspects of videoconference fatigue, and analyze relationships between videoconference characteristics and videoconference fatigue.

Through our examination, we contribute to scholarship in multiple ways. First, we utilize Attention Restoration Theory (ART; Kaplan, 1995) to provide a new theoretical lens to understand why individuals experience videoconference fatigue. ART is useful for this investigation because 1) it explicitly recognizes that fatigue is caused by sustained attention and 2) it provides unique insights beyond theories using work characteristics to explain how to minimize fatigue (Quinn et al., 2012). Second, we identify the nature of videoconference fatigue and differentiate it from overall work fatigue and other specific fatigue constructs (e.g., citizenship fatigue, compassion fatigue), highlighting the distinctiveness of this construct. Third, we assess the temporal nature of videoconference fatigue by replicating the non-linear daily trajectories of fatigue during a workday (Hülsheger, 2016) and discovering that deviations from an individual's normal daily fatigue trajectory can be caused by videoconferences at specific time points. Previous research suggests that work meetings are related to end-of-day fatigue (e.g., Loung \& Rogelberg, 2005; Rogelberg et al., 2006). We extend this body of research to show when videoconferences are more fatiguing. Explicitly integrating time into our exploration provides a novel contribution (e.g., Shipp \& Cole, 2015) that advances our understanding of human energy changes throughout the workday. Fourth, we challenge a common assumption that there is a "typical meeting," which has often resulted in assessing meetings as having an average, stable influence on employee well-being. Instead, we take Rogelberg et al.'s (2006) view that "meetings differ among themselves in several ways" (p. 95). This affords a more dynamic evaluation of the phenomenon and extends the meetings literature by capturing meeting-level differences. Drawing from ART (Kaplan, 1995), we focus on how participants can alter their 
videoconference-related behaviors (i.e., muting oneself, turning off video, etc.) in each meeting and experience varying levels of group belongingness that may lessen videoconference fatigue. These contributions have practical implications for organizations and workers because discovering ways to manage videoconference fatigue can reduce negative work-related outcomes of fatigue (e.g., job performance, citizenship behaviors; Sonnentag, 2015).

\section{Attention Restoration Theory}

ART is a theory about human energy that explains how energy is depleted specifically by sustained attention, which is the effort required to focus attention and process information (Kaplan, 1995). A critical contribution of ART is that it proposes that individual actions like "being away", "effortless attention", and "compatibility" can minimize fatigue or even replenish depleted energy in ways not explicitly described in other human energy frameworks (Quinn et al., 2012). Previous research 1) drew upon the work interruptions literature to explain that work meetings are fatiguing because they increase time demands or work hassles (e.g., Loung \& Rogelberg, 2005; Rogelberg et al., 2006), or 2) utilized affective events theory (AET; Weiss \& Cropanzano, 1996) to examine positive or negative attitudes caused by meetings as a discrete work event (Rogelberg et al., 2010). However, these previous frameworks are inadequate for this investigation for several reasons. First, the work characteristics framework does not capture characteristics specific to videoconferencing (e.g., mute), whereas ART provides a key insight in recognizing that energy is influenced by more than typical work demands and resources (Quinn et al., 2012). Second, AET is a broad theory used to explain relationships between affect with work attitudes and behaviors, but some have argued that AET fails to explain how, when, and why work events trigger emotional responses (Ashton-James \& Ashkansay, 2005). Instead, ART allows us to explore that videoconferences are associated with fatigue because of increased 
sustained attention (how), during certain times of day (when), and are influenced by specific videoconference characteristics (why).

\section{The Nature of Videoconference Fatigue}

The construct of videoconference fatigue was absent from our collective vocabulary until March 2020 when many U.S. professional workers began working from home due to the COVID-19 pandemic (Google Trends, https://bit.ly/3oe8PW6). Soon after, news contributors popularized the term through stories reporting how meeting participants felt exhausted following a videoconference, describing the phenomenon as "the impression of feeling overly drained after a period of meeting over a videoconference tool" (Nardi, 2020). Because our first contribution in this study is a conceptual one, we generate a testable and falsifiable definition of the phenomenon. Thus, we define videoconference fatigue as the degree to which people feel exhausted, tired, or worn out attributed to engaging in a videoconference.

Videoconference fatigue naturally fits within the broader domain of human energy, which is an affective construct expressing an individual's level of emotional activation (Quinn et al., 2012). Fatigue is the affective state of unpleasant deactivation (Yik et al., 2011) commonly described as feeling exhausted or tired (Quinn \& Dutton, 2005). Videoconference fatigue is conceptually similar to the more general construct of work fatigue, yet it is different from work fatigue in at least two ways. First, work fatigue is caused by general job demands (e.g., role overload, time demands) as well as non-work demands that spill over into work time (Frone \& Tidwell, 2015). Conversely, the causes of videoconference fatigue are importantly more specific than general job demands, such as avoiding distractions from technology and paying greater attention due to fewer nonverbal cues. Second, videoconference fatigue is temporally distinct. Work fatigue is conceptualized and measured as an end-of-workday feeling (Winwood et al., 
2005), whereas videoconference fatigue is conceptualized as a near-term feeling attributed to a specific event (i.e., a videoconference). Similar to other fatigue-related constructs such as citizenship fatigue (Bolino et al., 2015) and compassion fatigue (Joinson, 1992), the antecedents of videoconference fatigue are distinct and not related to other work demands. However, videoconference fatigue is different from these constructs because of its distinct temporal nature. For example, compassion fatigue is the result of cumulative and prolonged experiences (Coetzee \& Klopper, 2010), whereas videoconference fatigue can occur after just one event. In sum, we propose that videoconference fatigue is similar to other fatigue constructs, but it has distinct antecedents and a unique temporal structure - thus making videoconference fatigue a unique phenomenon that merits further study.

\section{Temporal Considerations of Videoconference Fatigue}

One temporal element that distinguishes videoconference fatigue from related constructs is event timing, which is a key aspect of understanding the theoretical relationships between constructs (Mitchell \& James, 2001). Event timing is critical because an experience during a certain time period can change an individual's fatigue state. Figure 1 provides different visual representations of how event timing can influence fatigue. Figure 1a considers a change in fatigue from a previous time point, such as how walks or relaxation exercises during employee lunch breaks reduce fatigue states (de Bloom et al., 2017). If changes in fatigue states are considered over a longer time period, a trajectory or pattern can be discovered (Figure 1b). Indeed, research has shown that, in general, individual feelings of fatigue change throughout the day in a nonlinear pattern, such that fatigue decreases in the first few hours and then steadily increases (Thayer, 1987). Another temporal consideration is how an experience alters this typical fatigue trajectory. This approach considers the shape of changes in fatigue over time (Figure 1c). 
For example, Hülsheger (2016) found that an employee's psychological detachment recovery experiences and sleep quality the previous evening changed the shape of the fatigue trajectory. However, during the workday, specific events at certain times can alter fatigue, and these alterations may be minor deviations (Figure 1d) or statistically significant deviations (Figure 1e) from one's expected trajectory. For example, the popular press suggests videoconferences later in the day may be more fatiguing (Williams, 2020). Therefore, we ask:

Research Question 1: When does videoconference fatigue occur?

\section{Videoconference Characteristics Associated with Videoconference Fatigue}

ART posits that individuals can reduce levels of fatigue in a few ways (Kaplan, 1995).

One possibility is by detaching from events that demand attentional resources. Referred to by ART as a sense of "being away," videoconference attendees may enable one of the following features to "detach": muting oneself, turning off one's webcam, or not looking at one's own video mirrored on-screen. ART also highlights that "compatibility" with one's environment (i.e., higher belongingness) and "fascination" or being in engaged in a task (i.e., higher voluntary attention; Kaplan \& Berman, 2010) can minimize fatigue. However, it is unclear what videoconference characteristics have stronger relationships with fatigue. For example, turning off the webcam should be related to lower fatigue because it provides relief from having to be "on" the entire meeting (i.e., higher detachment being related to lower fatigue). With this line of thinking, we could expect that using the webcam more often would be related to higher fatigue. Yet, using the webcam more often could also be related to lower fatigue because it can foster a personal connection among meeting attendees. Due to this lack of clarity, we explore:

Research Question 2: What videoconference characteristics are related to fatigue?

\section{Method}


We used a mixed methods approach combining quantitative and qualitative data collection to provide methodological triangulation by coupling measurement precision and authenticity of context (Turner et al., 2017). In order to obtain a diverse sample of employees working remotely during the COVID-19 pandemic, we employed multiple recruitment strategies. First, study participation invitations were sent via email through two young professional networking groups in different metropolitan cities in the southeastern United States. Second, we used the online panel Prolific to sample additional participants (Porter et al., 2019). Management scholars have used online panels to recruit a diverse sample of working adults in previous work meetings research (e.g., Shanock et al., 2013; Allen et al., 2018; Rogelberg et al., 2006) and in population sampling during the COVID-19 pandemic (e.g., Luchetti et al., 2020). Previous experience sampling studies have also used multiple recruitment strategies such as personal and professional networks, snowball sampling, and online panels (e.g., Lanaj et al., 2020; Trougakos et al., 2020). To be eligible, participants had to (a) be located in the Eastern US time zone (EDT/UTC-5; required so all surveys were sent during the same working hours), (b) work from home in some capacity due to the COVID-19 pandemic, (c) be 18 years old or older, (d) work at least 20 hours per week, and (e) have remote work meetings planned for the week of data collection. Individuals recruited through professional networks were incentivized with electronic gift cards. Participants received $\$ 5$ for completing the qualitative survey, $\$ 5$ for completing at least $10 \%$ of the quantitative surveys, $\$ 15$ for completing at least $50 \%$ of the quantitative surveys, and each survey completed was an entry into a lottery system for one of two \$100 gift cards. Individuals recruited through Prolific received an average payment rate of $\$ 21.40 /$ hour. This study was part of a larger data collection and the procedure was deemed exempt by Old Dominion University IRB \#1598432 titled Videoconference Fatigue. 
A total of 69 participants met the study eligibility criteria and consented to participate. These individuals were then contacted and had approximately five days to complete an initial demographic survey. Participants were removed from the dataset before analysis if they had low response rates (completed fewer than $50 \%$ of all quantitative surveys, $N=10$ ) or if their work conditions did not change significantly due to the COVID-19 pandemic (working from home only "a little", $N=1$; worked from home most or all of the time before the pandemic, $N=3)^{2}$. The final sample consisted of 55 individuals working in a wide range of industries (i.e., legal services, banking and finance, engineering, health care, education, information technology). The majority of participants were male (58.2\%) and White (72.7\%). On average, participants were 33.60 years old $(S D=9.05)$, spent $3.31(S D=1.37)$ years in their current job, and worked 43.82 $(S D=6.50)$ hours per week. Quantitative data was collected in 1-week phases from April 30 May 22, 2020. Qualitative data was collected September $2020^{3}$.

Participants received nine hourly surveys each workday (9:30 a.m. - 5:30 p.m.) for five consecutive working days (Monday - Friday), as well as a before-work survey available from 6 a.m. -9 a.m. All surveys had a time limit expiration such that participants could only complete a survey during a specified time (e.g., 9:30 a.m. - 10:29 a.m.). Table 1 provides information about all measures used in this study. We chose an interval-contingent design that sent a survey each hour because it is considered less intrusive than a random signal-contingent approach, is more appropriate for questions related to temporal phenomena, and minimizes the chance of noncompliance found in event-contingent designs because the routine survey schedule lessens

\footnotetext{
${ }^{2}$ We removed these individuals because it is possible that those who worked remotely pre-COVID-19 engaged in videoconference meetings and had already developed strategies to prevent or reduce videoconference fatigue. Including them could potentially suppress our ability to detect the phenomenon.

${ }^{3}$ We thank our reviewers for recommending a qualitative data collection to enhance our conceptualization of videoconference fatigue, improve our theorizing, and augment the practical implications of our research.
} 
participant's burden of remembering to complete a survey after each videoconference event

(Fisher \& To, 2012). A 5-day study design was chosen to minimize participant burden caused by completing hourly surveys ${ }^{4}$. Participants completed a total of 1,746 surveys during the week, participated in an average of 5.75 videoconference meetings across all five days, and when analyzed by day, individuals participated in zero videoconferences on $42.6 \%$ of the days, participated in one videoconference on $26.7 \%$ of the days, and participated in two or more videoconferences on $29.8 \%$ of the days.

We solicited responses to three open-ended questions: 1) You indicated that you have heard of "Zoom fatigue" or "videoconference fatigue." In your own words, please describe this phenomenon ${ }^{5}$; 2) Teleconferences are meetings held only over the phone, whereas videoconferences include the element of video (e.g., Zoom, Teams, Skype, FaceTime). Please describe your experiences meeting in-person vs. videoconference vs. teleconference. Do you feel the same or different during and after meetings of different modes? In what ways and when?; and 3) How have you changed the way you approach videoconference meetings since March 2020 (e.g., setting them at different times, using/not using your webcam or video)?

\section{Results}

\section{Qualitative Exploration}

To enhance our understanding of videoconference fatigue, we conducted a thematic analysis (Braun \& Clarke, 2006). Specifically, we engaged in an inductive analysis following Braun and Clarke's (2012) six-phase approach wherein we analyzed the responses to all questions and allowed themes to emerge from the data. In line with this procedure, we relied on

\footnotetext{
${ }^{4}$ See similar rationale for a 3-day interval-contingent study in French \& Allen, 2019.

5 This first question was only displayed if they indicated in a previous question that they had heard of "videoconference fatigue" or "Zoom fatigue."
} 
our theory (ART) to inform theme aggregation. Thirty-nine participants provided usable qualitative responses (70.9\% response rate). All authors met to consensus build around a definition of videoconference fatigue informed by responses to the first question. Three authors independently developed themes across the questions, then reconciled differences in themes and theme descriptions. Three major themes emerged. To provide additional support for the themes, two graduate students independently coded responses using the themes provided. We estimated inter-rater agreement by theme (Kurasaki, 2000). Agreement among the original and the two students' coding ranged from $77 \%$ to $97 \%$, supporting the original themes (Krippendorff, 2013).

The first theme included psychosomatic and psychological descriptions of the videoconference experience, which included feeling exhausted, fatigued, tired, drained, or worn out. As one respondent wrote about videoconferences, "Tired of being in them, extra tired after being in them." Another wrote that videoconference meetings "can be taxing on the mind and spirit." Overall, $92.9 \%$ of respondents mentioned a psychosomatic or psychological manifestation of fatigue when answering the first open-ended question, providing preliminary evidence of this unique experience.

The second theme captured the concept of time as it related to videoconferencing. This included the frequency of meetings such as being in videoconferences "all day," "all the time," or "back-to-back." Participants also referred to the length of videoconferences (e.g., "for extended periods"), when videoconferences were held (e.g., "Most of my [videoconferences] are in the mornings"), and how their energy waned throughout the day because of videoconferences (e.g., "I am also teaching 100\% virtual. In the morning I feel great, and ready to go, but by lunch, I can't stand staring at a computer screen"). Another participant mentioned that they "prefer to schedule [videoconferences] more towards the start of my workday as opposed to the end of the 
workday." Overall, participants provided insight about when videoconference fatigue occurred (RQ1), noting that it happened after multiple videoconference meetings, because of extended durations of screen time while videoconferencing, or due of the time of day of videoconferences.

The final theme included in-meeting causes of videoconference fatigue (RQ2) and ways in which participants tried to reduce this feeling. Notably, $87.2 \%$ of participants mentioned positive and negative aspects of one characteristic unique to videoconferences as opposed to other meeting types: the use of video/the webcam. One major cause of fatigue was the effort required to sustain attention during a videoconference. One participant wrote that they "get tired of feeling like they have to have their attention at 100 percent and continually staring into the camera the entire meeting." Another participant wrote that "I do feel more tired after videoconference meetings especially if my camera is on, because I feel that expectation to look at the camera all the time to pay attention." Other challenges included difficulty due to visual demands (e.g., paying more attention to attendees because of fewer nonverbal cues), technical problems (e.g., unable to hear someone clearly), or distractions such as other work. For example, one participant wrote, "I catch myself looking at my video, much more distracted, most of the time I end up working on something else while the call/video is running." Respondents also reported several ways they tried to manage videoconference fatigue during meetings including turning off their camera or enabling mute. As one participant put it, "I'm also more comfortable with opting to turn the camera off. I think I (and some of my colleagues) felt like we always had to be ON at first." Similarly, restructuring meetings by enacting rules to not do other work during meetings appeared to help participants pay attention more fully and experience less fatigue.

In addition to increased effortful attention, participants noted that the challenges associated with fostering personal connections during videoconferences also influenced fatigue. 
For example, one participant wrote that "video conferencing is quite impersonal. [E]veryone just wants to get in and get out, log in and log off. [T]here's very little chatter before and after the meeting like there would be in real life." Participants reported that turning on their webcam often helped to solve issues related to personal connection for themselves or for others. As two respondents wrote, "I have made a conscious effort to use video more often. For people not yet back to the office it helps them stay connected on a personal level," and "videoconferences are good to see others and have a bit of a connection." In all, the thematic analysis affords three key observations: 1) there is preliminary evidence that videoconference fatigue is a feeling of exhaustion caused by sustained attention during videoconferences, 2) time plays a role in attendees' experiences of videoconference fatigue, and 3) there are various ways in which attendees try to alleviate videoconference fatigue and these methods are consistent with core ideas of ART.

\section{Quantitative Exploration}

Table 2 provides the means, standard deviations, and correlations of variables at the meeting level. Intraclass coefficients indicated that $51.0 \%$ of the total variation in fatigue was between-person variation (i.e., an individual difference in fatigue across people), $9.8 \%$ was between-day variation (i.e., differences in fatigue related to the day of the week), and $39.2 \%$ was within-day variation (i.e., fatigue variation occurring within each day). This amount of variation at different levels is evidence that a multilevel approach is appropriate. We tested our research questions using recommended practices (see Appendix A for details of our analytic approach).

Research Question 1 asked when videoconference fatigue occurs, and the qualitative responses suggested that this happens at various time points throughout the day. To examine this research question empirically, we first tested a series of nested models to determine if and how 
fatigue levels change throughout the day (Table 3). Based on prior research (e.g., Hülsheger, 2016) we specified and compared a linear latent growth model and a quadratic growth model ${ }^{6}$. Consistent with Hülsheger (2016), we found the quadratic growth model to be the best fitting model and resulted in a significant improvement in model fit over a linear growth model (scaled $\left.\Delta \chi^{2}[4]=32.07, p<.01\right)$. Both the linear (coeff. $\left.=-.06, p=.006\right)$ and quadratic (coeff. $=.02, p=$ .000) slope factors were significant indicating that fatigue initially declines in the morning and then increases throughout the afternoon and early evening (similar to Figure 1b).

Having established the overall trajectory of fatigue throughout the day, we then tested whether having a videoconference explained additional variance in fatigue at a given time point over and above the natural trajectory of fatigue. To do so, we regressed the observed value of fatigue onto the videoconference variable (i.e., yes/no videoconference) from that time point. We also ran models with 1) lagged effects $(t-1)$ to see if having a videoconference in the previous hour affects fatigue levels in the following hour, and 2) other work in the past hour to determine if videoconferences have a greater impact on fatigue than performing other work. Table 4 shows the results of these analyses. Model fit of all three models were acceptable (Model 1: $\chi^{2}[100]=$ $170, \mathrm{CFI}=.96, \mathrm{RMSEA}=.05 ;$ Model $2: \chi^{2}[180]=306.04, \mathrm{CFI}=.95, \mathrm{RMSEA}=.05 ;$ Model 3 : $\left.\chi^{2}[172]=293.26, \mathrm{CFI}=.95, \mathrm{RMSEA}=.05\right)$. To aid our interpretation of the results we calculated the cumulative probability of significance for each coefficient using Bliese and Wang (2020) Formula 1. Cumulative probability of significance helps to address the limitations of relying on point estimates as it informs readers the probability of observing the results in a

\footnotetext{
${ }^{6}$ We compared model fit using the SB $\chi^{2}$ likelihood ratio (Satorra \& Bentler, 2010), as well as with differences in Akaike information criteria (AIC; Burnham \& Anderson, 2004), the comparative fit index (CFI), and the root mean square error of approximation (RMSEA). We considered CFI values greater than .95 and RMSEA values lower than .08 to be indicative of good fit (Kline, 2016). Better fitting models are those with significant change in SB $\chi^{2}$ and lower AIC values.
} 
particular sample. Four patterns of results emerged. One pattern is that videoconference meetings between 10:30 - 11:30 a.m. (captured in the Time 3 survey) were related to higher levels of fatigue consistently in all three models. A second pattern is that videoconferences in the early afternoon between 1:30 - 2:30 p.m. were related to higher fatigue at Time 6 (2:30 p.m. survey) or a lagged effect at Time 7 (3:30 p.m. survey) ${ }^{7}$. A third pattern is that videoconferences between 3:30 - 4:30 p.m. were related to higher fatigue at Time 8 (4:30 p.m. survey) or a lagged fatigue effect at Time 9 (5:30 p.m. survey). These three patterns indicate that videoconferences are associated with fatigue levels higher than one's expected fatigue trajectory at different times of the day (as illustrated in Figure 1e), even after controlling for other work conducted in the past hour. Interestingly, a fourth pattern that emerged is a negative effect at Time 5 (1:30 p.m. survey) and lagged negative effect at Time 6 survey (2:30 p.m. survey), meaning that levels of fatigue were lower than the expected trajectory that can potentially be attributed to a videoconference.

Research Question 2 examined the relationships between videoconference characteristics and fatigue. For these analyses, data were used only if the participant had one videoconference since the last survey and if they completed the current as well as the previous survey. The final dataset for this analysis contained 279 observations. To justify multilevel modeling, we tested an unconditional model for post-videoconference fatigue (i.e., a model with no predictors) and then tested whether the change in the -2-log likelihood (i.e., deviance) statistic was significant when we add our predictors using a scale corrected chi-square test (Hox et al., 2017) ${ }^{8}$. The log likelihood comparisons were significant $\left(\Delta \mathrm{SB} \chi^{2}(7)=43.71, p<.001\right)$ and the AIC was

\footnotetext{
${ }^{7}$ This finding indicates that videoconferences may have a fatiguing effect immediately after or one hour after the videoconference. This is not the same as testing the cumulative effect of videoconferences, such as an accumulation effect of multiple videoconferences on fatigue. We did test the effect of the total number of videoconferences on fatigue at the end of the day. Total number of meetings was not statistically significant with end-of-day fatigue. Complete results of this analysis are available from the first author.

${ }^{8}$ A traditional chi-square difference test cannot be performed with the MLR estimator.
} 
similarly reduced $(\triangle \mathrm{AIC}=26.45)$, thus indicating an improvement in fit over the null model when predictors are added. Multilevel regression results are provided in Table 5. Controlling for fatigue in the previous survey, turning the webcam off $(\gamma=-.09, p=.08)$, watching oneself $(\gamma=-$ $.09, p=.29)$, attention during the meeting $(\gamma=-.08, p=.25)$, and videoconference meeting duration $(\gamma=.00, p=.98)$ had no statistically significant impact on post-meeting fatigue. However, muting one's microphone $\mathrm{e}^{9}(\gamma=-.09, p=.02)$ and perceptions of group belongingness had a negative relationship with fatigue $(\gamma=-.21, p=.003)$. Collectively, these multilevel analyses support ideas within the ART framework that both psychological experiences (i.e., belongingness) and technology behavior (i.e., using mute) are related to lower levels of fatigue.

\section{Post Hoc Analysis}

However, it seems possible that these two characteristics could have a synergistic interaction (e.g., strengthening the relationship with fatigue) or a restricted variance interaction, such that as certain values of one characteristic changes (i.e., belongingness), other values on another characteristic (i.e., mute) become less plausible (Cortina et al., 2019). For example, an individual could feel a high level of group belongingness and be less likely to use mute (i.e., talk more), or an individual could have a low level of group belongingness and use mute for most of the meeting. In fact, perceptions of group belongingness and mute share a significant negative zero-order correlation $(r=-.45, p<.01)$, indicating that perceptions of higher belongingness in

\footnotetext{
${ }^{9}$ Readers will note that the correlation between microphone use and fatigue is not significant, indicating a type of suppression effect. We explored this further and determined that this significant weight for microphone use was what Friedman and Wall (2005) call enhancement, which is a form of suppression in which an independent variable is unrelated to the dependent variable but is related to other independent variables and increases total $R^{2}$ (i.e., $\left|\widehat{\beta}_{1}\right|>$ $\left|r_{y 1}\right|$ and $\left.R^{2}>r_{y 1}^{2}+r_{y 2}^{2}\right)$. This means that variance explained in $\mathrm{Y}$ goes down if this predictor is excluded.

Friedman and Wall detail several ways in which $R^{2}$ can increase because of suppression and one of those ways is by suppressing irrelevant variance in another predictor. Although the sign of the weight may not mean much, as is generally the case in the presence of high collinearity, $\Delta R^{2}$ is still meaningful. Friedman and Wall go so far as to say that "discarding variables with small or zero correlation with the criterion is not necessarily a good idea when maximum $R^{2}$ is desired" (p. 130) and also advocate that suppressor variables "should not be ignored" (p. 131). Thus, we interpret this relationship as our goal is to understand what contributes to (or reduces) videoconference fatigue.
} 
this sample is associated with less muting, and lower belongingness is related to more muting. Given that theory (ART) and our empirical results suggest that higher levels of both belongingness and mute are related to lower fatigue, but that these characteristics may not cooccur at high levels, we tested the interaction of these two variables.

Standardized multilevel regression results indicated a statistically significant interaction term (see Appendix Table 1), which is visualized in Figure 2. Overall, this interaction shows that mute levels do not impact fatigue at high levels of group belongingness, indicating the importance of group belongingness to reduce videoconference fatigue. For individuals with low group belongingness, not using the mute function has a compensatory effect, meaning that meeting attendees who reported lower group belongingness but had their microphone on (i.e., less mute) experienced less fatigue post-meeting. Interestingly, the highest levels of fatigue occurred when individuals reported high use of mute and low levels of group belongingness, which we suspect is similar to findings that task disengagement is related to higher mental fatigue (Hopstaken et al., 2015).

\section{Discussion}

During the COVID-19 global pandemic, social distancing measures meant that many inperson meetings shifted to remote meetings, often held via videoconference. In this study, we examined the videoconference fatigue phenomenon, which we define as the degree to which people feel exhausted, tired, or worn out attributed to engaging in a videoconference. The extreme case of the COVID-19 pandemic, which caused many workers to shift to a virtual work environment, offers a unique opportunity to explore this phenomenon because extreme cases are advantageous when seeking evidence of previously subtle relationships (Chen, 2016). 
Using a mixed methods design of qualitative open-ended responses and quantitative data from hourly assessments across one work week, our study resulted in three core findings that can influence the science and practice of meetings and enhance our theoretical understanding of fatigue. First, results of our thematic analysis suggest that videoconference fatigue is a unique construct. This experience, first reported by the media, was confirmed by $92.9 \%$ of the participants in our qualitative survey. Recognizing and naming this experience is important because videoconference meetings are generally viewed as beneficial (e.g., more efficient; Lantz, 2001; more productive; Rosetti \& Surynt, 1985); pinpointing videoconference fatigue can hopefully help minimize reductions of these benefits. Additionally, although related to general work fatigue, the causes of videoconference fatigue are distinct from those of general work fatigue. Videoconference fatigue also tends to occur closer in temporal proximity to the experience (i.e., the videoconference), which is different from work fatigue (typically described as end of workday fatigue) and different from fatigue caused by prolonged experiences (e.g., citizenship fatigue). Because videoconference meetings may have distinct characteristics that influence fatigue, the existing meetings literature may not extend to videoconference meetings, thus highlighting the importance of scientific inquiry aimed at this phenomenon.

Second, we show that it is not simply the act of having a videoconference meeting that can alter fatigue, but when that videoconference occurs. Qualitative responses indicated that time played an important role in understanding videoconference fatigue, and the empirical analyses provided more precise examination as to when this occurs. Latent growth results indicate that videoconference meetings are associated with higher fatigue at certain times of the day, with more instances occurring later in the day. However, the relationship with lower fatigue at the mid-day time point (1:30 p.m.) suggests that videoconference meetings could be beneficial. It 
might be that a mid-day videoconference meeting reduces the after-lunch decrease in attention (Smith \& Miles, 1986), or it could be that individuals reported lower fatigue because of an effective lunch break (Bosch et al., 2018). This unexpected finding warrants further research. These findings contribute to the overall understanding of worker fatigue and extends general ideas about employee fatigue trajectories occurring in a nonlinear pattern (Hülsheger, 2016) by demonstrating that specific events influence fatigue beyond the expected trajectory. Importantly, this contributes to our theoretical understanding of fatigue trajectories by examining how work events influence fatigue throughout the day, supplementing previous research on how work experiences alter energy levels over days (e.g., Chawla et al., 2019), months (e.g., Hatch et al., 2019), and years (e.g., Fan et al., 2019). Our use of latent growth analysis with time-varying covariates also provides a useful template for how future researchers can create similar models to understand how measures of a time-specific construct can influence temporal patterns of another construct. In addition, this finding highlights the need to include timing in organizational theorizing (Morgeson et al., 2015), as time itself can alter the relationships between other constructs (Shipp \& Cole, 2015).

Third, this study utilized theoretical framing from ART, which provided new insights because it specifically identifies sustained attention as causing fatigue and proposes that "compatibility" and "being away" can reduce fatigue, ideas that are not explained in theoretical frameworks typically used in the meetings literature (e.g., work characteristics, AET). The qualitative responses highlighted that a variety of characteristics affect the degree of fatigue experienced, and the quantitative analyses tested the relations between some of these characteristics and fatigue. Combined, the findings from this study suggest that individuals can feel less fatigued when they experience a higher sense of belonging with fellow attendees or find 
ways to reduce attentional demands using videoconference technology (i.e., mute), which mirror ART's propositions. Testing the interaction of these two characteristics suggested that even if group belongingness is low, fatigue is also lower if the individual uses mute less (i.e., actively participates in the meeting). These finding highlight the importance of considering the impact of videoconference characteristics on employee well-being, especially when employees are physically distant from each other, and represents a particularly fruitful avenue for future research. Given ART's consideration of sustained attention and its suggestion that behaviors and activities that enhance compatibility or provide a sense of detachment can reduce the harmful effects of sustained attention, it is likely that ART will be a particularly useful framework for future inquiries regarding the relation between videoconference fatigue and well-being.

\section{Practical Implications}

Given that videoconferences are expected to continue beyond the COVID-19 pandemic, it is important to provide clear practical recommendations as to how videoconference fatigue can be reduced. We make several recommendations based on the results of our quantitative and qualitative analysis in Table 6 . We also provide theoretical explanations of how these recommendations may affect fatigue as well as current evidence regarding their effectiveness.

\section{Limitations and Future Directions}

There are limitations of this study that provide avenues for future research. First, although we tested the most common recommendations for reducing videoconference fatigue, we were not able to test all possible ways through which one may reduce videoconference fatigue, such as whether efforts to foster personal connections at the beginning of the call through "chit chat" (Methot et al., 2020) may lessen fatigue (please see Table 6 for additional future directions). Second, although we found that the nonlinear trajectory of fatigue in a quadratic 
pattern was stable between individuals and days, this finding may only apply to the five consecutive workdays for employees with the ability to work remotely in a traditional (MondayFriday) work week. Future research should explore changes in fatigue trajectories occurring throughout multiple weeks, longer periods of respite such as weekends (e.g., Hahn et al., 2012), and individuals with nontraditional work arrangements (e.g., Campion et al., 2020). Relatedly, a third potential limitation of this study is that we focused on post-meeting fatigue. This was a valuable inquiry, however, work on citizenship fatigue suggests that fatigue can accumulate in the long-term and affect whether someone engages in future citizenship behaviors (Bolino et al., 2015). Our participants suggested that videoconferencing may also have long-term effects: "People start to get tired of and dislike online videoconferences like Zoom" and "People have grown tired of such meetings.” Future research should examine the long-term build-up of videoconference fatigue and whether this influences individuals' willingness to participate in future videoconferences, as well as their pre-meeting and in-meeting attitudes and behaviors. Fourth, though we focused on fatigue (i.e., low energy) because we were examining the videoconference fatigue phenomenon, investigating changes in vigor (i.e., high energy) is an important future research direction because fatigue and vigor deplete and replenish for different reasons and at different rates (Bennett et al., 2020). Lastly, we did not consider the effect of remote meeting content (e.g., the meeting topic) on videoconference fatigue; however, ART suggests that when individuals are intrinsically interested in meeting content, paying attention may come naturally and thus not be fatiguing (Kaplan, 1995). Therefore, we suggest that future research considers the moderating effect of meeting content on videoconference fatigue.

\section{Conclusion}


The COVID-19 pandemic has accelerated the long-predicted trend of remote work (Niles, 1975; Raghuram et al., 2019). Indeed, even as social distancing recommendations ease, a recent survey of CFOs found that $74 \%$ planned to permanently move some of their positions to remote positions (Gartner, Inc., 2020). Thus, remote work and videoconferences are likely to become more common. The term videoconference fatigue suggests that videoconferences harm employee well-being; however, results of our study suggest that there are aspects of videoconference meetings (e.g., group belongingness, mute, time of day) that alter fatigue. Videoconference meeting participants can use these strategies to reduce their fatigue. 


\section{References}

Allen, J. A., Lehmann-Willenbrock, N., \& Rogelberg, S. G. (2018). Let's get this meeting started: Meeting lateness and actual meeting outcomes. Journal of Organizational Behavior, 39(8), 1008-1021. https://doi.org/10.1002/job.2276

Ashton-James, C. E., \& Ashkanasy, N. M. (2005). What lies beneath? A process analysis of affective events theory. Research on emotion in organizations, 1, 23-46.

Bennett, A. A., Gabriel, A. S., \& Calderwood, C. (2020). Examining the interplay of micro-break durations and activities for employee recovery: A mixed-methods investigation. Journal of Occupational Health Psychology, 25(2), 126-142. https://doi.org/10.1037/ocp0000168

Bliese, P. D., Edwards, J. R., \& Sonnentag, S. (2017). Stress and well-being at work: A century of empirical trends reflecting theoretical and societal influences. Journal of Applied Psychology, 102(3), 389-402. https://doi.org/10.1037/ap10000109

Bliese, P. D., \& Wang, M. (2020). Results provide information about cumulative probabilities of finding significance: Let's report this information. Journal of Management, 46(7), 12751288. https://doi.org/10.1177/0149206319886909

Bolino, M. C., Hsiung, H. H., Harvey, J., \& LePine, J. A. (2015). “Well, I'm tired of tryin'!” Organizational citizenship behavior and citizenship fatigue. Journal of Applied Psychology, 100 (1), 56-74. https://doi.org/10.1037/a0037583

Bosch, C., Sonnentag, S., \& Pinck, A. S. (2018). What makes for a good break? A diary study on recovery experiences during lunch break. Journal of Occupational and Organizational Psychology, 91(1), 134-157. https://doi.org/10.1111/joop.12195

Braun, V., \& Clarke, V. (2006). Using thematic analysis in psychology. Qualitative research in Psychology, 3(2), 77-101. https://doi.org/10.1191/1478088706qp063oa 
Braun, V., \& Clarke, V. (2012). Thematic analysis. In H. Cooper, P. M. Camic, D. L. Long, A. T. Panter, D. Rindskopf, \& K. J. Sher (Eds.), APA handbook of research methods in psychology, Vol. 2. Research designs: Quantitative, qualitative, neuropsychological, and biological (p. 57-71). American Psychological Association. https://doi.org/10.1037/13620-004

Bryk, A. S., \& Raudenbush, S. W. (1992). Hierarchical linear models: Applications and data analysis methods. Newberry Park, CA: Sage Publications.

Burnham, K. P., \& Anderson, D. R. (2004). Multimodel inference: understanding AIC and BIC in model selection. Sociological Methods \& Research, 33(2), 261-304. https://doi.org/10.1177/0049124104268644

Campion, E. D., Caza, B. B., \& Moss, S. E. (2020). Multiple jobholding: An integrative systematic review and future research agenda. Journal of Management, 46(1), 165-191. https://doi.org/10.1177/0149206319882756

Chatman, J. A., \& Flynn, F. J. (2001). The influence of demographic heterogeneity on the emergence and consequences of cooperative norms in work teams. Academy of Management Journal, 44(5), 956-974

Chawla, N., MacGowan, R. L., Gabriel, A. S., \& Podsakoff, N. P. (2020). Unplugging or staying connected? Examining the nature, antecedents, and consequences of profiles of daily recovery experiences. Journal of Applied Psychology, 105(1), 19-39. https://doi.org/10.1037/apl0000423

Chen, K. K. (2016). Using extreme cases to understand organizations. In K. D. Elsbach and R. M. Kramer (Eds.). Handbook of Qualitative Organizational Research: Innovative Pathways and Methods (pp. 33 - 44). Routledge. https://doi.org/10.4324/9781315849072 
Coetzee, S. K., \& Klopper, H. C. (2010). Compassion fatigue within nursing practice: A concept analysis. Nursing \& Health Sciences, 12, 235-243.

Cortina, J. M., Koehler, T., Keeler, K. R., \& Nielsen, B. B. (2019). Restricted variance interaction effects: What they are and why they are your friends. Journal of Management, 45(7), 2779-2806. https://doi.org/10.1177/0149206318770735

Davis, F. D., \& Yi, M. Y. (2004). Improving computer skill training: behavior modeling, symbolic mental rehearsal, and the role of knowledge structures. Journal of Applied Psychology, 89(3), 509-523. https://doi.org/10.1037/0021-9010.89.3.509

Denstadli, J. M., Julsrud, T. E., \& Hjorthol, R. J. (2012). Videoconferencing as a mode of communication: A comparative study of the use of videoconferencing and face-to-face meetings. Journal of Business and Technical Communication, 26(1), 65-91. https://doi.org/10.1177/1050651911421125

Fan, W., Moen, P., Kelly, E. L., Hammer, L. B., \& Berkman, L. F. (2019). Job strain, time strain, and well-being: A longitudinal, person-centered approach in two industries. Journal of Vocational Behavior, 110, 102-116. https://doi.org/10.1016/j.jvb.2018.10.017

Fisher, C. D., \& To, M. L. (2012). Using experience sampling methodology in organizational behavior. Journal of Organizational Behavior, 33(7), 865-877. https://doi.org/10.1002/job.1803

Fosslien, L., \& Duffy, M. W. (2020). How to combat zoom fatigue. Harvard Business Review. https://hbr.org/2020/04/how-to-combat-zoom-fatigue

French, K. A., \& Allen, T. D. (2019). Episodic work-family conflict and strain: A dynamic perspective. Journal of Applied Psychology, Advance online publication. https://doi.org/10.1037/ap10000470 
Friedman, L., \& Wall, M. (2005). Graphical views of suppression and multicollinearity in multiple linear regression. The American Statistician, 59(2), 127-136. https://doi.org/10.1198/000313005X41337

Frone, M. R., \& Tidwell, M. C. O. (2015). The meaning and measurement of work fatigue: Development and evaluation of the Three-Dimensional Work Fatigue Inventory (3DWFI). Journal of Occupational Health Psychology, 20, 273-288. https://doi.org/10.1037/a0038700

Gabriel, A. S., Podsakoff, N. P., Beal, D. J., Scott, B. A., Sonnentag, S., Trougakos, J. P., \& Butts, M. M. (2019). Experience sampling methods: A discussion of critical trends and considerations for scholarly advancement. Organizational Research Methods, 22(4), 9691006. https://doi.org/10.1177/1094428118802626

Gartner, Inc. (2020, April 3). Gartner CFO survey reveals $74 \%$ intend to shift some employees to remote work permanently [press release]. https://www.gartner.com/en/newsroom/pressreleases/2020-04-03-gartner-cfo-surey-reveals-74-percent-of-organizations-to-shiftsome-employees-to-remote-work-permanently2.

Geimer, J. L., Leach, D. J., DeSimone, J. A., Rogelberg, S. G., \& Warr, P. B. (2015). Meetings at work: Perceived effectiveness and recommended improvements. Journal of Business Research, 68, 2015-2026. https://doi.org/10.1016/j.jbusres.2015.02.015

Geldhof, G. J., Preacher, K. J., \& Zyphur, M. J. (2014). Reliability estimation in a multilevel confirmatory factor analysis framework. Psychological Methods, 19(1), 72-91. https://doi.org/10.1037/a0032138 
Gully, S. M., Devine, D. J., \& Whitney, D. J. (2012). A meta-analysis of cohesion and performance: Effects of level of analysis and task interdependence. Small Group Research, 43(6), 702-725. https://doi-org.proxy.lib.odu.edu/10.1177/1046496412468069

Hackman, J. R. (1992). Group influences on individuals in organizations. In M. D. Dunnette \& L. M. Hough (Eds.), Handbook of Industrial and Organizational Psychology $\left(2^{\text {nd }}\right.$ ed., Vol. 3, pp. 199-267). Palo Alto, CA: Consulting Psychologists Press.

Hahn, V. C., Binnewies, C., \& Haun, S. (2012). The role of partners for employees' recovery during the weekend. Journal of Vocational Behavior, 80(2), 288-298. https://doi.org/10.1016/j.jvb.2011.12.004

Hatch, D. J., Potter, G. G., Martus, P., Rose, U., \& Freude, G. (2019). Lagged versus concurrent changes between burnout and depression symptoms and unique contributions from job demands and job resources. Journal of Occupational Health Psychology, 24(6), 617-628. http://dx.doi.org/10.1037/ocp0000170

Hopstaken, J. F., Van Der Linden, D., Bakker, A. B., \& Kompier, M. A. (2015). A multifaceted investigation of the link between mental fatigue and task disengagement. Psychophysiology, 52(3), 305-315. https://doi.org/10.1111/psyp.12339

Hox, J. J., Moerbeek, M., \& Van de Schoot, R. (2017). Multilevel analysis: Techniques and applications. New York, NY: Routledge.

Hülsheger, U. R. (2016). From dawn till dusk: Shedding light on the recovery process by investigating daily change patterns in fatigue. Journal of Applied Psychology, 101(6), 905-914. https://doi.org/10.1037/ap10000104 
Hunter, E. M., \& Wu, C. (2016). Give me a better break: Choosing workday break activities to maximize resource recovery. Journal of Applied Psychology, 101(2), 302-311. https://doi.org/10.1037/apl0000045

Jiang, M. (2020). The reason Zoom calls drain your energy. Remote Control, BBC. https://www.bbc.com/worklife/article/20200421-why-zoom-video-chats-are-soexhausting

Joinson, C. (1992). Coping with compassion fatigue. Nursing, 22(4), 116-118.

Kaplan, S. (1995). The restorative benefits of nature: Toward an integrative framework. Journal of Environmental Psychology, 15(3), 169-182. https://doi.org/10.1016/0272$\underline{4944(95) 90001-2}$

Kaplan, S., \& Berman, M. G. (2010). Directed attention as a common resource for executive functioning and self-regulation. Perspectives on Psychological Science, 5(1), 43-57. https://doi.org/10.1177/1745691609356784

Kline, R. B. (2016). Principles and practice of structural equation modeling. New York, NY: Guilford Press.

Kraut, R. E., Rice, R. E., Cool, C., \& Fish, R. S. (1998). Varieties of social influence: The role of utility and norms in the success of a new communication medium. Organization Science, 9(4), 437-453. https://doi.org/10.1287/orsc.9.4.437

LaHuis, D. M., Hartman, M. J., Hakoyama, S., \& Clark, P. C. (2014). Explained variance measures for multilevel models. Organizational Research Methods, 17, 433-451. https://doi.org/10.1177/1094428114541701 
Lanaj, K., Gabriel, A. S., \& Chawla, N. (2020). The self-sacrificial nature of leader identity: Understanding the costs and benefits at work and home. Journal of Applied Psychology, Advance online publication. https://doi.org/10.1037/ap10000505

Lantz, A. (2001). Meetings in a distributed group of experts: Comparing face-to-face, chat and collaborative virtual environments. Behaviour \& Information Technology, 20(2), 111117. https://doi.org/10.1080/01449290010020693

Luchetti, M., Lee, J. H., Aschwanden, D., Sesker, A., Strickhouser, J. E., Terracciano, A., \& Sutin, A. R. (2020). The trajectory of loneliness in response to COVID-19. American Psychologist. Advanced Online Publication. http://dx.doi.org/10.1037/amp0000690

Luong, A., \& Rogelberg, S. G. (2005). Meetings and more meetings: The relationship between meeting load and the daily well-being of employees. Group Dynamics: Theory, Research, and Practice, 9(1), 58-67. https://doi.org/10.1037/1089-2699.9.1.58

Mauer, R. (2020, April 6). Virtual happy hours help co-workers, industry peers stay connected. SHRM. https://www.shrm.org/hr-today/news/hr-news/pages/virtual-happy-hours-helpcoworkers-stay-connected.aspx

McNair, D. M., Lorr, M., \& Droppleman, L. F. (1971). Manual for the profile of mood states (POMS). San Diego: Educational and Industrial Testing Service.

Methot, J. R., Rosado-Solomon, E., Downes, P., \& Gabriel, A. S. (2020). Office Chit-Chat as a Social Ritual: The Uplifting Yet Distracting Effects of Daily Small Talk at Work. Academy of Management Journal. https://doi.org/10.5465/amj.2018.1474

Mitchell, T. R., \& James, L. R. (2001). Building better theory: Time and the specification of when things happen. Academy of Management Review, 26, 530-547. https://doi.org/10.5465/amr.2001.5393889 
Morgeson, F. P., Mitchell, T. R., \& Liu, D. (2015). Event system theory: An event-oriented approach to the organizational sciences. Academy of Management Review, 40(4), 515537. https://doi.org/10.5465/amr.2012.0099

Muthén, L. K., \& Muthén, B. O. (1998-2017). Mplus user’s guide. Muthén \& Muthén: Los Angeles, CA.

Nardi, C. (2020, August 4). Nearly three out of every four Canadians say virtual conferencing tools an 'excellent' alternative to interacting in person. National Post. https://nationalpost.com/news/canada/nearly-three-out-of-four-canadians-says-virtualconferencing-tools-are-an-excellent-alternative-to-interacting-in-person

Porter, C. O., Outlaw, R., Gale, J. P., \& Cho, T. S. (2019). The use of online panel data in management research: A review and recommendations. Journal of Management, 45(1), 319-344. https://doi.org/10.1177/0149206318811569

PwC. (2020, June 25). When everyone can work from home, what's the office for? https://www.pwc.com/us/en/library/covid-19/us-remote-work-survey.html

Quinn, R. W., \& Dutton, J. E. (2005). Coordination as energy-in-conversation. Academy of Management Review, 30(1), 36-57. https://doi.org/10.5465/amr.2005.15281422

Quinn, R. W., Spreitzer, G. M., \& Lam, C. F. (2012). Building a sustainable model of human energy in organizations: Exploring the critical role of resources. Academy of Management Annals, 6(1), 337-396. https://doi.org/10.5465/19416520.2012.676762

Raghuram, S., Hill, N. S., Gibbs, J. L., \& Maruping, L. M. (2019). Virtual work: bridging research clusters. Academy of Management Annals, 13, 308-341.

Reichers, A. E. (1987). An interactionist perspective on newcomer socialization rates. Academy of Management Review, 12, 278-287. 
Rogelberg, S. G., Allen, J. A., Shanock, L., Scott, C., \& Shuffler, M. (2010). Employee satisfaction with meetings: A contemporary facet of job satisfaction. Human Resource Management, 49(2), 149-172. https://doi.org/10.1002/hrm.20339

Rogelberg, S. G., Leach, D. J., Warr, P. B., \& Burnfield, J. L. (2006). "Not another meeting!” Are meeting time demands related to employee well-being? Journal of Applied Psychology, 91(1), 83-96. https://doi.org/10.1037/0021-9010.91.1.83

Rosetti, D. K., \& Surynt, T. J. (1985). Video teleconferencing and performance. The Journal of Business Communication, 22(4), 25-31. https://doi.org/10.1177/002194368502200404

Satorra, A. \& Bentler, P.M. (2010). Ensuring positiveness of the scaled difference chi-square test statistic. Psychometrika 75: 243. doi:10.1007/s11336-009-9135-y

Shanock, L. R., Allen, J. A., Dunn, A. M., Baran, B. E., Scott, C. W., \& Rogelberg, S. G. (2013). Less acting, more doing: How surface acting relates to perceived meeting effectiveness and other employee outcomes. Journal of Occupational and Organizational Psychology, 86(4), 457-476. https://doi.org/10.1111/joop.12037

Shipp, A. J., \& Cole, M. S. (2015). Time in individual-level organizational studies: What is it, how is it used, and why isn't it exploited more often? Annual Review or Organizational Psychology and Organizational Behavior, 2, 237-260. https://doi.org/10.1146/annurevorgpsych-032414-111245

Smith, A. P., \& Miles, C. (1986). Effects of lunch on selective and sustained attention. Neuropsychobiology, 16(2-3), 117-120. https://doi.org/10.1159/000118309

Sonnentag, S. (2015). Dynamics of well-being. Annual Review of Organizational Psychology and Organizational Behavior, 2, 261-293. https://doi.org/10.1146/annurev-orgpsych$\underline{032414-111347}$ 
Spataro, J. (2020). The future of work - the good, the challenging \& the unknown.

https://www.microsoft.com/en-us/microsoft-365/blog/2020/07/08/future-work-goodchallenging-unknown/

Tan, X., Shiyko, M. P., Li, R., Li, Y., \& Dierker, L. (2012). A time-varying effect model for intensive longitudinal data. Psychological Methods, 17, 61-77. http://dx.doi.org/10.1037/a0025814

Thayer, R. E. (1987). Problem perception, optimism, and related states as a function of time of day (diurnal rhythm) and moderate exercise: Two arousal systems in interaction. Motivation and Emotion, 11, 19-36. https://doi.org/10.1007/BF00992211

Trougakos, J. P., Chawla, N., \& McCarthy, J. M. (2020). Working in a pandemic: Exploring the impact of COVID-19 health anxiety on work, family, and health outcomes. Journal of Applied Psychology. http://dx.doi.org/10.1037/ap10000739

Turner, S. F., Cardinal, L. B., \& Burton, R. M. (2017). Research design for mixed methods: A triangulation-based framework and roadmap. Organizational Research Methods, 20(2), 243-267. https://doi.org/10.1177/1094428115610808

Weiss, H. M., \& Cropanzano, R. (1996). Affective Events Theory: A theoretical discussion of the structure, causes and consequences of affective experiences at work. In B. M. Staw \& L. L. Cummings (Eds.), Research in organizational behavior: An annual series of analytical essays and critical reviews, (Vol. 18, pp. 1-74).

Williams, M. E. (2020). My virtual social life is exhausting: Turns out Zoom cocktail hours can burn you out, too. Salon. https://www.salon.com/2020/04/03/my-virtual-social-life-is$\underline{\text { exhausting-turns-out-zoom-cocktail-hours-can-burn-you-out-too }}$ 
Winwood, P. C., Winefield, A. H., Dawson, D., \& Lushington, K. (2005). Development and validation of a scale to measure work-related fatigue and recovery: The Occupational Fatigue Exhaustion/Recovery Scale (OFER). Journal of Occupational and Environmental Medicine, 47, 594-606. https://doi.org/10.1097/01.jom.0000161740.71049.c4

World at Work (2020). Back to work playbook study. www.worldatwork.org/docs/research-andsurveys/20200528_BacktoWorkPlaybook.pdf.

Wright, T. A., \& Cropanzano, R. (1998). Emotional exhaustion as a predictor of job performance and voluntary turnover. Journal of Applied Psychology, 83, 486-493. https://doi.org/10.1037/0021-9010.83.3.486 
Table 1

Measures Used in Study

\begin{tabular}{|c|c|c|c|c|}
\hline Variable & $\begin{array}{l}\text { Number } \\
\text { of items }\end{array}$ & Measure & Item & Scale anchors \\
\hline Attention & 1 & Davis and Yi (2004) & "I paid close attention during the meeting" & $\begin{array}{l}\text { 6-point scale from } \\
\text { "strongly disagree" to } \\
\text { "strongly agree" }\end{array}$ \\
\hline $\begin{array}{l}\text { Microphone off } \\
\text { (mute) }\end{array}$ & 1 & & $\begin{array}{l}\text { "During your most recent meeting, how often did you use } \\
\text { mute?" }\end{array}$ & $\begin{array}{l}\text { 5-point scale from "never" } \\
\text { to "all of the time." }\end{array}$ \\
\hline Watches self & 1 & & $\begin{array}{l}\text { "During the most recent videoconference, how often did you } \\
\text { look at yourself on the screen?" }\end{array}$ & $\begin{array}{l}\text { 5-point scale from "never" } \\
\text { to "all of the time." }\end{array}$ \\
\hline $\begin{array}{l}\text { Group } \\
\text { belongingness }\end{array}$ & 1 & $\begin{array}{l}\text { Work Group } \\
\text { Integration scale } \\
\text { (Kraut et al., 1998) }\end{array}$ & $\begin{array}{l}\text { "Consider the individuals who were in your most recent } \\
\text { meeting and rate your level of agreement: I feel part of the } \\
\text { group" }\end{array}$ & $\begin{array}{l}\text { 6-point scale from } \\
\text { "strongly disagree" to } \\
\text { "strongly agree" }\end{array}$ \\
\hline Work past hour & 1 & & "Have you completed any work-related tasks in the past hour?" & \\
\hline $\begin{array}{l}\text { Videoconference } \\
\text { meeting }\end{array}$ & 1 & & $\begin{array}{l}\text { "How many work meetings have you had since the last survey? } \\
\text { What type of meeting was your most recent meeting? } \\
\text { (videoconference, teleconference, electronic chat)" }\end{array}$ & \\
\hline
\end{tabular}

Note. All variables were measured in the hourly surveys (sent from 9:30 a.m. to 5:30 p.m.). Fatigue was also measured in the morning before work. Videoconference characteristics assessed using shortened 1-item measures of constructs to minimize work interruption, which is similar to other event-based survey designs (e.g., Hunter \& Wu, 2016) and is reasonable for constructs with a single dimension (Gabriel et al., 2019). If participants had multiple meetings during the previous hour, they were asked to respond to the items considering their most recent meeting. ${ }^{\mathrm{a}} \mathrm{We}$ computed Cronbach's alpha and $\omega$ at the within-day $(\alpha=.90, \omega=.90)$, between-day $(\alpha=.94, \omega=.95)$, and between-person $(\alpha=.97, \omega=.97)$ levels using multilevel confirmatory factor analysis (e.g., Geldhof et al., 2014). 
Table 2

Means, Standard Deviations, and Correlations among Study Variables at Meeting Level

\begin{tabular}{lccccccccc}
\hline & $\mathrm{M}$ & $\mathrm{SD}$ & 1 & 2 & 3 & 4 & 5 & 6 & 7 \\
\hline 1 Fatigue $(t-1)$ & 1.99 & 1.05 & & & & & & & \\
2 Fatigue & 2.04 & 1.07 & $.53^{* *}$ & & & & & \\
3 Attention & 4.97 & 1.12 & $-.15^{*}$ & -.08 & & & & \\
4 Microphone off (mute) & 2.65 & 1.53 & .14 & -.01 & $-.49^{* *}$ & & & \\
5 Webcam off & 2.13 & 1.67 & .08 & -.09 & $-.32^{* *}$ & $.42^{* *}$ & & & \\
6 Watching oneself & 1.96 & .88 & .05 & .03 & .18 & $-.18^{*}$ & $-.53^{* *}$ & & \\
7 Group belongingness & 5.04 & 1.00 & -.15 & $-.26^{* *}$ & $.50^{* *}$ & $-.45^{* *}$ & $-.30^{* *}$ & $.19^{*}$ & \\
8 Meeting duration & 37.90 & 19.91 & .09 & .02 & .06 & .21 & -.01 & .05 & -.08 \\
\hline
\end{tabular}

Note. Correlations are at the between-meeting level $(N=279)$ hourly observations nested within 5 days within 55 employees). Fatigue $(t-1)$ is fatigue measured at the previous time point. ${ }^{*} p<.05 .{ }^{* *} p<.01$. 
Table 3

Test and Comparison of Latent Growth Trajectories of Fatigue

\begin{tabular}{|c|c|c|c|c|c|c|c|c|c|c|c|c|}
\hline Model & $\chi^{2}$ & $d f$ & $\mathrm{scr}$ & CFI & RMSEA & {$[90 \% \mathrm{CI}]$} & AIC & $\triangle \mathrm{AIC}$ & $\Delta \mathrm{SB} \chi^{2}$ & $\Delta \mathrm{scr}$ & $\Delta d f$ & $p$ \\
\hline Linear & 171.89 & 40 & 1.68 & 0.91 & 0.11 & {$[.09, .13]$} & 4475.95 & & & & & \\
\hline Quadratic & 89.42 & 36 & 1.25 & 0.96 & 0.07 & {$[.06, .09]$} & 4402.35 & 73.6 & 32.07 & 5.49 & 4 & $<.01$ \\
\hline
\end{tabular}

Note. AIC $=$ Akaike information criteria CFI $=$ comparative fit index $; \chi^{2}=$ chi-square value given by maximum likelihood robust estimator; $90 \% \mathrm{CI}=90 \%$ confidence interval associated with RMSEA; $d f=$ degrees of freedom; $p=$ significance of the $\Delta \mathrm{SB} \chi^{2}$; RMSEA = root mean square error of approximation; $\mathrm{scr}=$ scaling correction factor; $\Delta \mathrm{AIC}=$ change in AIC; $\Delta d f=$ difference in $d f$; $\Delta \mathrm{SB} \chi^{2}=$ corrected differences in SB chi-square; $\Delta \mathrm{scr}=\operatorname{src}$ for $\Delta \mathrm{SB} \chi^{2}$. 
Table 4

Parameter Estimates for Quadratic Latent Growth Model of Fatigue with Time-Varying Covariates

\begin{tabular}{|c|c|c|c|c|c|c|c|c|c|c|c|c|}
\hline & \multicolumn{4}{|c|}{ Model 1} & \multicolumn{4}{|c|}{ Model 2} & \multicolumn{4}{|c|}{ Model 3} \\
\hline & Coeff. & SE & $t$-value & $\begin{array}{c}\text { Cum. } \\
\text { Prob. }(\%)\end{array}$ & Coeff. & SE & $t$-value & $\begin{array}{c}\text { Cum. } \\
\text { Prob. }(\%)\end{array}$ & Coeff. & SE & $t$-value & $\begin{array}{c}\text { Cum. } \\
\text { Prob. (\%) }\end{array}$ \\
\hline \multicolumn{13}{|l|}{ Time 1 (9:30 a.m. survey) } \\
\hline Videoconference meeting & .11 & $(.09)$ & 1.22 & 22.31 & .14 & $(.10)$ & 1.40 & 28.01 & .07 & $(.11)$ & .64 & 9.03 \\
\hline Other work & & & & & -.17 & $(.15)$ & -1.13 & 19.74 & -.28 & $(.22)$ & -1.27 & 23.79 \\
\hline \multicolumn{13}{|l|}{ Time 2 (10:30 a.m. survey) } \\
\hline Videoconference meeting $(t-1)$ & -.09 & $(.08)$ & -1.25 & 23.21 & & & & & -.12 & $(.08)$ & -1.5 & 31.43 \\
\hline Videoconference meeting & -.13 & $(.08)$ & -1.63 & 35.99 & -.14 & $(.08)$ & -1.75 & 40.75 & -.08 & $(.08)$ & -1.00 & 16.31 \\
\hline Other work & & & & & -.05 & $(.10)$ & -.50 & 7.03 & -.17 & $(.25)$ & .68 & 9.69 \\
\hline \multicolumn{13}{|l|}{ Time 3 (11:30 a.m. survey) } \\
\hline Videoconference meeting $(t-1)$ & -.09 & $(.07)$ & -1.29 & 24.44 & & & & & $.08^{* *}$ & $(.03)$ & 2.67 & 75.30 \\
\hline Videoconference meeting & $.14^{*}$ & $(.07)$ & 2.00 & 50.62 & $.19^{* *}$ & $(.07)$ & 2.71 & 76.51 & $.21^{* *}$ & $(.07)$ & 3.00 & 84.44 \\
\hline Other work & & & & & -.05 & $(.08)$ & -.63 & 8.84 & -.20 & $(.44)$ & -.45 & 6.34 \\
\hline \multicolumn{13}{|l|}{ Time 4 (12:30 p.m. survey) } \\
\hline Videoconference meeting $(t-1)$ & .08 & $(.10)$ & .80 & 11.94 & & & & & .12 & $(.16)$ & .75 & 10.94 \\
\hline Videoconference meeting & -.01 & $(.08)$ & -.13 & 3.32 & .06 & $(.05)$ & 1.20 & 21.72 & -.10 & $(.20)$ & -.50 & 6.98 \\
\hline Other work & & & & & .10 & (.09) & 1.11 & 19.19 & -.01 & $(.52)$ & -.02 & 2.55 \\
\hline \multicolumn{13}{|l|}{ Time 5 (1:30 p.m. survey) } \\
\hline Videoconference meeting $(t-1)$ & -.03 & $(.05)$ & -.60 & 8.45 & & & & & -.08 & $(.09)$ & -.89 & 13.76 \\
\hline Videoconference meeting & .01 & $(.09)$ & .11 & 3.18 & $-.15^{* *}$ & $(.06)$ & -2.50 & 69.63 & -.16 & $(.19)$ & -.84 & 12.70 \\
\hline Other work & & & & & $.15^{*}$ & $(.07)$ & 2.14 & 56.16 & .06 & $(.63)$ & .10 & 3.06 \\
\hline \multicolumn{13}{|l|}{ Time 6 (2:30 p.m. survey) } \\
\hline Videoconference meeting $(t-1)$ & $-.19^{* *}$ & $*(.05)$ & -3.80 & 96.39 & & & & & -.14 & $(.12)$ & -1.17 & 20.82 \\
\hline Videoconference meeting & .07 & $(.06)$ & 1.17 & 20.86 & $.15^{*}$ & $(.07)$ & 2.14 & 56.16 & $.16^{*}$ & $(.08)$ & 2.00 & 50.62 \\
\hline Other work & & & & & .03 & $(.06)$ & .50 & 7.03 & -.09 & $(.49)$ & -.18 & 3.65 \\
\hline \multicolumn{13}{|l|}{ Time 7 (3:30 p.m. survey) } \\
\hline Videoconference meeting $(t-1)$ & $.12^{* *}$ & $*(.05)$ & 2.40 & 66.07 & & & & & .14 & $(.20)$ & .70 & 10.03 \\
\hline Videoconference meeting & .18 & $(.13)$ & 1.38 & 27.34 & .14 & $(.12)$ & 1.17 & 20.86 & .14 & $(.11)$ & 1.27 & 23.79 \\
\hline
\end{tabular}




\begin{tabular}{|c|c|c|c|c|c|c|c|c|c|c|c|}
\hline Other work & & & & .10 & $(.07)$ & 1.43 & 29.02 & -.04 & $(.28)$ & -.14 & 3.34 \\
\hline \multicolumn{12}{|l|}{ Time 8 (4:30 p.m. survey) } \\
\hline Videoconference meeting $(t-1)$ & $.17 \quad(.11)$ & 1.54 & 32.88 & & & & & .03 & $(.10)$ & .30 & 4.69 \\
\hline Videoconference meeting & $.32^{* *}(.09)$ & 3.56 & 93.98 & $.17^{\text {** }}$ & $(.04)$ & 4.25 & 98.73 & .25 & $(.14)$ & 1.79 & 42.30 \\
\hline Other work & & & & $.12^{* *}$ & $(.04)$ & 3.00 & 84.39 & -.06 & $(.11)$ & -.55 & 7.66 \\
\hline \multicolumn{12}{|l|}{ Time 9 (5:30 p.m. survey) } \\
\hline Videoconference meeting $(t-1)$ & $.30^{* *}(.11)$ & 2.72 & 76.82 & & & & & $.35^{* *}$ & $(.08)$ & 4.38 & 99.12 \\
\hline Videoconference meeting & $.03 \quad(.27)$ & .11 & 3.18 & .24 & $(.20)$ & 1.20 & 21.72 & .24 & $(.14)$ & 1.71 & 39.20 \\
\hline Other work & & & & .07 & $(.06)$ & 1.17 & 20.86 & -.15 & $(.44)$ & -.34 & 5.09 \\
\hline
\end{tabular}

Note. $N=274$ days. (55 employees for 5 days; 1 person was missing all data from 1 day). Videoconference meeting is dichotomous ( 0 $=$ no videoconference, $1=$ videoconference). Videoconference meeting $(t-1)$ is the lagged effect of a videoconference meeting at the previous time point. Other work is a dichotomous variable $(0=$ no work; $1=$ any work in past hour $)$. Model 1: Videoconference meetings and lagged videoconference meetings as time-varying covariates of fatigue. Model 2: Videoconference meetings, lagged videoconference meetings, and other work at time-varying covariates of fatigue. Unstandardized estimates shown. ${ }^{*} p<.05 .{ }^{* *} p<.01$. 
Table 5

Results of Multilevel Regression of Fatigue

\begin{tabular}{lcc}
\hline Variable & \multicolumn{2}{c}{ Fatigue } \\
\hline Intercept & SE \\
Fatigue $(t-1)$ & $2.02^{* *}$ & $(.13)$ \\
Videoconference characteristics & $.52^{* *}$ & $(.11)$ \\
$\quad$ Attention & & \\
Microphone off (mute) & -.08 & $(.07)$ \\
Webcam off & $-.09^{*}$ & $(.04)$ \\
Watching oneself & -.09 & $(.05)$ \\
Group belongingness & -.09 & $(.08)$ \\
Meeting Duration & $-.21^{* *}$ & $(.07)$ \\
\hline
\end{tabular}

Note. $N=279$ hourly observations (nested within 55 individuals across 5 days). Using the formula by Bryk and Raudenbush (1992) as suggested by LaHuis et al. (2014), this model explains $16 \%$ of the variance in fatigue. Unstandardized estimates provided. Fatigue $(t-$ 1) is fatigue measured at the previous time point and used as a control variable in this analysis. ${ }^{*} p<.05 .{ }^{* *} p<.01$. 
Table 6

Recommendations for Reducing Videoconference Fatigue

\begin{tabular}{|c|c|c|c|}
\hline $\begin{array}{l}\text { Recommendations } \\
\text { Supported by our } \\
\text { Quantitative Study }\end{array}$ & Potential Explanation for Fatigue Reduction & Current State of Evidence & $\begin{array}{l}\text { Future Research } \\
\text { Directions }\end{array}$ \\
\hline $\begin{array}{l}\text { 1. Hold meetings at a } \\
\text { time that is least fatiguing } \\
\text { for as many participants } \\
\text { as possible based on } \\
\text { work schedule, which } \\
\text { may be earlier in the } \\
\text { work period. }\end{array}$ & $\begin{array}{l}\text { Human energy levels, including fatigue levels, can } \\
\text { fluctuate over the course of a day, and past research } \\
\text { suggests that certain experiences can alter an } \\
\text { individual's fatigue trajectory (Hülsheger et al., 2016). } \\
\text { Given that meetings are affect-generating events } \\
\text { (Rogelberg et al., 2010), they may influence fatigue } \\
\text { trajectories throughout the day. }\end{array}$ & $\begin{array}{l}\text { Results of our quantitative } \\
\text { study suggested that meetings } \\
\text { at different times of day } \\
\text { affected individuals' fatigue } \\
\text { beyond their expected } \\
\text { trajectories. Fatigue was higher } \\
\text { than expected at more } \\
\text { timepoints later in the day. }\end{array}$ & $\begin{array}{l}\text { Although holding } \\
\text { meetings at certain times } \\
\text { may be less fatiguing, } \\
\text { additional research is } \\
\text { needed to determine the } \\
\text { productivity-fatigue } \\
\text { tradeoff that may exist. }\end{array}$ \\
\hline $\begin{array}{l}\text { 2. Enhance perceptions o } \\
\text { group belongingness. }\end{array}$ & $\begin{array}{l}\text { Enhancing perceptions of group belonginess is expected } \\
\text { to reduce fatigue by making attendees feel more } \\
\text { connected with each other and more interested in } \\
\text { participating in the meeting, thus reducing effortful } \\
\text { attention and fatigue (Kaplan \& Berman, 2010). }\end{array}$ & $\begin{array}{l}\text { Theory suggests that when } \\
\text { individuals are given the } \\
\text { opportunity to interact socially } \\
\text { with others, they are more } \\
\text { likely to feel part of a group } \\
\text { (e.g., Reichers, 1987). } \\
\text { In our quantitative study, higher } \\
\text { feelings of group belongingness } \\
\text { were associated with less post- } \\
\text { meeting fatigue. }\end{array}$ & $\begin{array}{l}\text { There are several } \\
\text { different ways for } \\
\text { employees to interact } \\
\text { socially, including } \\
\text { allowing meeting } \\
\text { attendees to chit-chat } \\
\text { (Methot et al., 2020), } \\
\text { organizing happy hours } \\
\text { (Maurer, 2020), etc. More } \\
\text { research is needed to } \\
\text { determine the best way to } \\
\text { build perceptions of } \\
\text { group belongingness } \\
\text { during videoconferences. }\end{array}$ \\
\hline $\begin{array}{l}\text { 3. Unless you are } \\
\text { speaking, mute your } \\
\text { microphone. }\end{array}$ & $\begin{array}{l}\text { ART (Kaplan, 1995) suggests that fatigue is caused by } \\
\text { the mental effort required to sustain attention, but that } \\
\text { individuals can reduce fatigue in a variety of ways, such } \\
\text { as "detaching" from meeting characteristics that cause }\end{array}$ & $\begin{array}{l}\text { Results of our quantitative } \\
\text { study indicated that individuals } \\
\text { who muted themselves during } \\
\text { meetings experienced less }\end{array}$ & $\begin{array}{l}\text { Future research should } \\
\text { consider the influence of } \\
\text { mute on attendees' } \\
\text { willingness to speak up }\end{array}$ \\
\hline
\end{tabular}


distraction or require sustained attention. By using mute when not speaking, distractions such as background noise are avoided, making it easier for everyone in the meeting to pay attention with less effort. Furthermore, using mute may reduce the amount of time one spends worrying about maintaining a quiet atmosphere during meetings, which could also reduce fatigue levels.

\section{Recommendations with Inconclusive Evidence from our Quantitative Study}

\section{Decrease/increase} webcam usage.
Turning off one's webcam is another way to "detach" that may reduce fatigue by reducing the number of stimuli on one's computer screen to be distracted by. Furthermore, having one's video off may also reduce the time one spends worrying about what their colleagues will think about how they look, their facial expressions, how clean their house is, etc., resulting in less fatigue. Indeed, several participants noted that one reason they felt videoconferences were fatiguing was because they felt pressure to be "on" and pay more attention to their "looks and attire."

However, keeping one's webcam on may enhance the extent to which one feels connected and engaged with the other meeting attendees, thus increasing feelings of group belongingness. For instance, one participant stated that they use their webcam more often because, "For people not yet back to the office it helps them stay fatigue. However, results of the and whether this affects interaction between group belongingness and mute found belongingness. that at low levels of group belongingness, using mute more frequently was related to increased fatigue, whereas use of mute had no apparent relation with fatigue when group belongingness perceptions were high.

\section{Current State of Evidence Future Research} Directions

$\begin{array}{ll}\text { Results of our quantitative } & \text { Additional research is } \\ \text { study were inconclusive. } & \text { needed to better } \\ \text { Individuals who indicated that } & \text { understand the two } \\ \text { they did not use their webcam } & \text { competing perspectives } \\ \text { reported less fatigue; however, } & \text { on how webcam usage } \\ \text { this effect was not statistically } & \text { affects videoconference } \\ \text { significant. } & \text { fatigue and whether there } \\ & \text { are specific circumstances } \\ & \text { in which one strategy } \\ & \text { might be more effective } \\ & \text { than the other. }\end{array}$

Results of our quantitative study were inconclusive. (did nols who indic this effect was not statistically significant. might be more effective 
connected on a personal level." Given that higher group

belongingness is related to less fatigue, leaving one's

webcam on may reduce fatigue if it increases a feeling

of group belongingness.

5. Consider using 'hide When one's video is displayed on their own screen, self' view.

there is a greater number of stimuli with which to be distracted. Indeed, one participant noted "I catch myself looking at my video, much more distracted." Therefore to reduce the amount of stimuli onscreen, one can use 'hide self' view, which should ultimately result in less fatigue. Although others may still be looking at your video, being unable to see it yourself may reduce the amount of time that you spend worrying about how you or your background look while still enhancing group belongingness, resulting in less fatigue.

In our quantitative study, we how often they looked at themselves during the meeting. frequently. In fact, the mean for

\section{Recommendations Based on Qualitative \\ Comments}

6. Take breaks during videoconferences (e.g., look away from the screen, stand up and wat around) and between videoconferences.

\section{Potential Explanation for Fatigue Reduction} Breaks (either during meetings or between meetings) give participants an opportunity to detach, which is a key way that individuals can reduce fatigue according to reduce fatigue levels (Bennett ART (Kaplan, 1995). For instance, one participant noted et al., 2020). "I sometimes turn off my webcam for brief periods if I need to get up and walk away from my computer or take a short break." Furthermore, it is particularly important to consider breaks when one is videoconferencing, if they are not naturally built in between meetings. As one participant noted, "there are nonstop zoom meetings back to back every hour or so all day. There's no time in between to take a break of walk or chat with others like it would be in real life/in person." asked participants to indicate It is possible that participants may not have been consciously aware of how often they looked fatigue.

at themselves or felt

uncomfortable indicating that they looked at themselves that item was comparatively low (1.95). short micro-breaks, can help

To better understand whether looking at oneself affects fatigue, future research should test whether using 'hide self' mode results in less Current State of Evidence Evidence sug
short micro-b
reduce fatigue
et al., 2020). Future research is needed to determine if breaks can affect videoconference fatigue specifically. 


\begin{tabular}{|c|c|c|c|}
\hline $\begin{array}{l}\text { 7. Establish group norms } \\
\text { (e.g., usage of mute and } \\
\text { webcam, acceptability of } \\
\text { multitasking, when/how } \\
\text { to speak up). }\end{array}$ & $\begin{array}{l}\text { Establishing group norms may reduce fatigue in two } \\
\text { ways. First, when strong norms exist, individuals will } \\
\text { experience less ambiguity regarding what acceptable } \\
\text { behavior is and when such behavior should occur (e.g., } \\
\text { Hackman, 1992). Thus, when norms exist, individuals } \\
\text { will not need to expend effort worrying about what they } \\
\text { should do, which should reduce fatigue (Kaplan, 1995). } \\
\text { Indeed, one participant noted, "I think some of this } \\
\text { fatigue happens because we aren't sure what the } \\
\text { expectations are of the meeting. Am I allowed to talk? } \\
\text { Should I turn on my camera?" } \\
\text { Second, when strong norms exist, individuals may feel } \\
\text { more strongly connected to the group, which should } \\
\text { enhance their level of interest and engagement in the } \\
\text { meeting, and thus result in less fatigue (Kaplan, 1995). }\end{array}$ & $\begin{array}{l}\text { There is extant evidence that } \\
\text { group norms are associated } \\
\text { with higher levels of cohesion } \\
\text { and productivity (e.g., Chatman } \\
\text { \& Flynn, 2001; Gully et al., } \\
\text { 1995). }\end{array}$ & $\begin{array}{l}\text { More research is needed } \\
\text { to determine if the } \\
\text { existence of group norms } \\
\text { related to } \\
\text { videoconferences } \\
\text { decreases } \\
\text { videoconference fatigue. }\end{array}$ \\
\hline
\end{tabular}


Figure 1

Illustrative Examples of How Time Impacts Fatigue

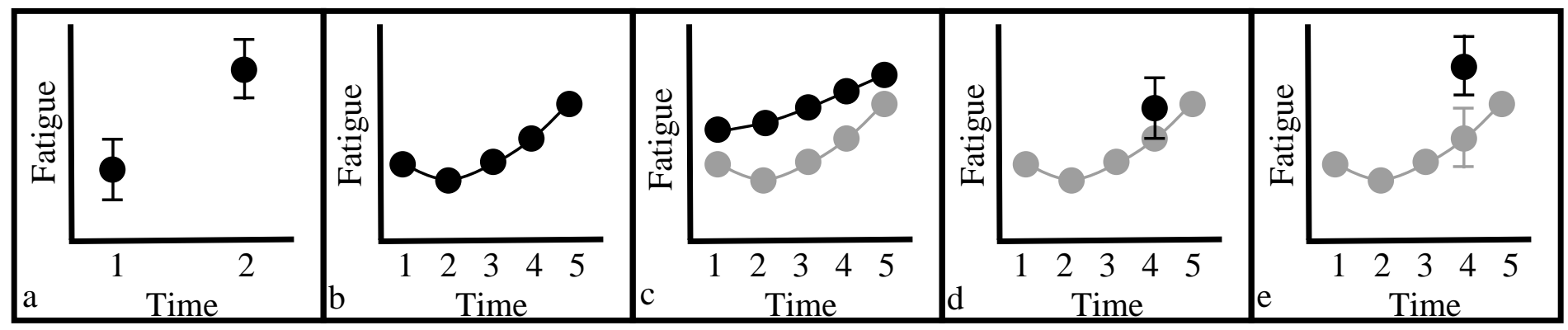

Note. Panel (a) illustrates how fatigue can change from one time point to another. Panel (b) illustrates how fatigue changes over time throughout the day with a typical trajectory. Panel (c) illustrates how fatigue trajectories may differ between days or between individuals. The grey trajectories in Panels (c), (d), and (e) are the same as in Panel b, black dots or trajectories illustrates a possible change. Panels (d) and (e) illustrate how an experience at a certain time may create deviations from one's expected trajectory, and that deviation may be minimal (d) or a statistically significant different level from one's expected trajectory (e). 
Figure 2

Figure of Interaction between Mute and Group Belongingness on Fatigue

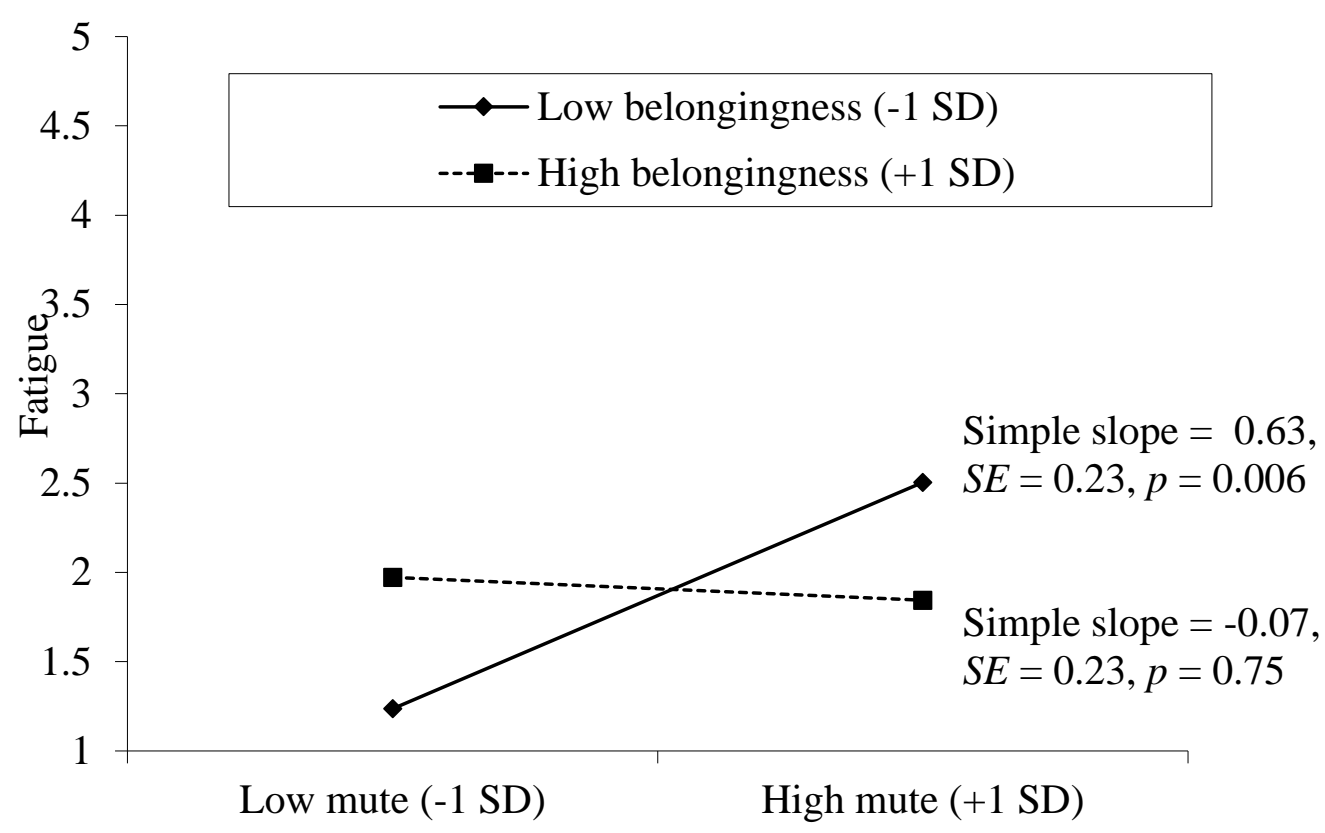




\section{Appendix}

\section{Empirical Analytic Approach}

Analyses were completed using Mplus 8.4 (Muthén \& Muthén, 1998-2017). To explore how videoconference meetings impacted fatigue throughout the day (Research Question 1), we utilized latent growth analysis with videoconference meetings included as time-varying covariates of fatigue ${ }^{10}$. Time-varying effect models are useful in studying the temporal change of a construct (i.e., fatigue) and how a covariate (i.e., videoconference) influences the construct at each specific time point accounting for the temporal patterns (Tan et al., 2012). The effects of videoconference characteristics on fatigue (Research Question 2) were tested using multilevel modeling in which videoconferences were nested within days, which were nested within individuals. We within-person centered Level 1 predictors, which removed variance that could be attributed to between-day factors (e.g., Monday compared to Tuesday variations) and between-person factors like individual differences in fatigue or survey response tendencies (Enders \& Tofighi, 2007). We controlled for each person's previous level of fatigue because this measure captures the negative effects of any previous work (e.g., feeling fatigued from videoconferences earlier in the day $)^{11}$.

\footnotetext{
${ }^{10} \mathrm{We}$ used the sandwich estimator to take into account the clustered nature of our data (i.e., observations nested within days). This estimator has been shown to provide unbiased and robust estimation of standard errors for clustered data (Rogers, 1993; White, 1980). We specified this estimator in Mplus by using the syntax TYPE=COMPLEX.

${ }^{11}$ We did not control for the previous amount of videoconferences during the day because the previous fatigue level captures the fatigue that could be caused by videoconferences earlier in the workday or any other reason for fatigue. For the first hourly survey sent at 9:30 a.m., the previous level of fatigue was measured in the before-work survey.
} 
Appendix Table 1

Results of Multilevel Regression of Fatigue with Interaction

\begin{tabular}{lrr}
\hline & \multicolumn{2}{c}{ Fatigue } \\
\cline { 2 - 3 } Variable & \multicolumn{2}{c}{ SE } \\
\hline Intercept & $1.89^{* *}$ & $(.10)$ \\
Fatigue $(t-1)$ & $.35^{* *}$ & $(.07)$ \\
Meeting characteristics & & \\
$\quad$ Attention & -.07 & $(.06)$ \\
Microphone off (mute) & .28 & $(.17)$ \\
Webcam off & -.01 & $(.06)$ \\
Watching oneself & -.03 & $(.05)$ \\
Group belongingness & .02 & $(.09)$ \\
Meeting Duration & -.01 & $(.05)$ \\
Mute X Group belongingness & $-.35^{*}$ & $(.15)$ \\
\hline
\end{tabular}

Note. $N=279$ hourly observations (nested within 55 individuals across 5 days). Using the formula by Bryk and Raudenbush (1992) as suggested by LaHuis et al. (2014), this model explains $17 \%$ of the variance in fatigue. Standardized estimates provided to more easily interpret the interaction with variables on different scales (Mute was measured on a 5-point scale and Group Belongingness was measured on a 6-point scale). Fatigue $(t-1)$ is fatigue measured at the previous time point and used as a control variable in this analysis. ${ }^{*} p<.05 .{ }^{* *} p<.01$. 